\title{
CAMUS, Carmen; CASTRO Cristina; CAMUS Julia. Translation Ideology and Gender, Newcastle: Cambridge Scholars Publishing, 2017, 201 p.
}

Alane Melo da Silva ${ }^{1}$

${ }^{1}$ Universidade Federal do Ceará, Fortaleza, Ceará, Brasil

O livro Translation Ideology and Gender surgiu como resultado da Primeira Conferência Internacional "Tradução, Ideologia e Gênero", realizada em Santander, Espanha em novembro de 2015. A obra reúne nove artigos, que discorrem sobre a representação feminina na literatura, sociedade, ciência e na área médica. O objetivo das organizadoras foi trazer uma contribuição para o conhecimento sobre tradução, ideologia e gênero em diferentes contextos geográficos e em diferentes épocas. O livro está divido em três partes: A primeira parte apresenta artigos que tratam da questão da tradução e gênero na área da saúde; A segunda parte aborda a questão da tradução, ideologia e gênero nas narrativas literárias e poéticas e a terceira parte apresenta a questão política de gênero e identidade.

O primeiro artigo de Vanessa Leonardi intitulado Gênero, Linguagem e Tradução nas Ciências da Saúde: Preconceitos de Gênero em Livros Médicos explora as questões de gênero, ideologia e sexismo em livros didáticos de medicina. Sob uma perspectiva feminista, a pesquisa realizada por Leonardi descobriu uma masculinização da linguagem e tentativa de apagamento da figura feminina na ciência, sendo a mulher quase sempre representada em posição inferior em 
relação ao homem, sempre representado de forma sóbria e ocupando cargos de poder na maioria dos livros didáticos médicos.

Todos os teóricos feministas parecem compartilhar uma preocupação comum com a eliminação de papéis de gênero injustos, lutando contra o fenômeno do sexismo. Leonardi cita Lepschy (1991, p.118) para quem o problema não reside na gramática, mas sim no discurso, não podendo, portanto, ser eliminado apenas através de mudanças nas regras gramaticais, uma vez que é caracterizado por questões complexas relacionadas a atitudes culturais e sociais.

No artigo, a autora dá o exemplo da língua italiana que como muitas outras, baseiam-se em um contexto antropocêntrico: o homem é o parâmetro em torno do qual o universo linguístico gira e se organiza. Um exemplo paradigmático: a própria palavra «homem» tem um duplo sentido porque pode referir-se tanto ao «macho da espécie» como também às «espécies em geral», enquanto a palavra «mulher»se refere apenas à «fêmea da espécie». A linguagem é o espelho de sua sociedade e a maneira como é usada pode refletir ideologias particulares de discriminação. Assim, a linguagem nunca é neutra e representa as normas e convenções sociais, juntamente com suas formas de domínio e discriminação.

O segundo artigo da primeira parte, de Keltoma Guerch tem por título: "As barreiras linguísticas, econômicas, educacionais e geográficas que privam a maioria das mulheres amazighs dos cuidados adequados com a saúde". A autora afirma que a história do Marrocos está principalmente ligada aos seus habitantes nativos, chamados amazighs, descendentes do rei Mazigh, um nativo de Iêmen. A presença física dos amazighs se estende do Egito até a Mauritânia constituindo $45 \%$ da população marroquina e compreendendo três grandes grupos étnicos. Um dos principais objetivos da pesquisa foi determinar as consequências da falta de infraestrutura adequada e corpo médico fluente em amazigh na área rural, e como isso afeta as mulheres desse povo e prejudicam o acesso a tratamentos 
de saúde. Na pesquisa realizada com profissionais da saúde, os entrevistados relataram não ter recebido treinamento adequado para ajudá-los a lidar com a cultura e especificidades linguísticas de seus pacientes amazighs. Além da barreira da língua, quase todos os 70 médicos entrevistados concordaram que as mulheres amazighs não contam totalmente seus problemas de saúde por causa da timidez, do analfabetismo e da incapacidade de expressar seus problemas de saúde. A maioria das mulheres amazighs (80\%) é dona de casa ou meninas solteiras que não puderam terminar sua educação. Além disso, as mulheres amazighs vivem em áreas que não podem beneficiar plenamente as campanhas médicas, sem um intérprete para garantir a comunicação entre médico e paciente. Entre fatores culturais destaca a incapacidade das mulheres de falar sobre seus corpos e necessidades médicas. Esse resultado é apoiado no relatório do Dr. Semlali, segundo o qual o analfabetismo no Marrocos é estimado em $43 \%$, e é ainda maior entre as mulheres, atingindo 54,7\% (Semlali 2010, p.11). Assim, uma das soluções apontadas por ativistas amazighs é o acesso à educação para as mulheres amazighs, com um maior respeito à sua própria língua e cultura.

A segunda parte do livro aborda a questão da tradução, ideologia e gênero nas narrativas literárias e poéticas. O primeiro artigo dessa seção de Pilar Godayol se intitula: Simone de Beauvoir: Censura e recepção na Ditadura Franquista. O objetivo do artigo é contribuir para a bibliografia da recepção na Espanha da obra Le deuxième sexe, de Simone de Beauvoir. Simone de Beauvoir é uma das principais autoras feministas da história, Le deuxième sexe, de sua autoria é considerada como um dos pilares do feminismo moderno. Godayol observa que durante o regime franquista as mulheres espanholas tinham um papel secundário na sociedade e o acesso a livros feministas, ou de cunho político de esquerda não era permitido pela ditadura. Castellet refere-se a Le deuxième sexe como "uma das obras que mais polêmicas suscitaram e que foram objeto de muitos comentários no último ano na França” (1949, p. 8). Com base nas conclusões de Beauvoir, Castellet ataca o 
tradicional papel das mulheres espanholas e compara-o com o das mulheres francesas libertadas e emancipadas.

$\mathrm{Na}$ época do franquismo, as mulheres espanholas estavam em um estado muito atrasado em relação às mulheres nos países da Europa do Norte e nos Estados Unidos. (Castellet 1949, p.9) com falta de liberdade social e cultural. Logo após a publicação do Le deuxième sexe, o Vaticano proibiu a leitura do livro, ao lado dos mais de quatro mil outros títulos. Dezenove anos depois da publicação do original em Paris, quinze depois da tradução inglesa e catorze depois da tradução argentina, Le deuxième sexe foi publicado pela primeira vez na Espanha, em catalão. O clássico livro feminista de Beauvoir foi uma obra crucial para os discursos feministas que surgiram na Espanha na década de 1960.

O segundo artigo da parte dois de Pilar Somacarrera se intitula: Reescrita e autocensura sexual na tradução de um romance canadense. Na Espanha, o regime autoritário de Francisco Franco (1939-1975) estabeleceu um severo sistema de censura, que regulava a entrada e a tradução de qualquer material impressso ou audiovisual (livros, teatro e filmes). Como observa Alberto Lázaro, esse sistema foi altamente influente no desenvolvimento da vida cultural espanhola por quatro décadas (2004, p.22). Desde os primórdios do franquismo, e mesmo durante a Guerra Civil Espanhola, a censura visava disseminar as doutrinas do regime, orientadas para a "prevalência da verdade" e a tarefa da "reconstrução nacional" (Abellán, 1980, p.15). A autora cita o caso da tradução para o espanhol de A Jest of God de Margaret Laurence (1926-1987), uma escritora e ativista política canadense. Durante o regime de Franco, os tradutores tiveram que ser especialmente cuidadosos com a linguagem sexual porque a sexualidade era um dos tópicos "negros". Os censores consideraram a tradução como evidência crucial para tomar sua decisão, porque o grau de aceitabilidade do livro reescrito dependia em grande medida da extensão em que o tradutor havia exercido a auto-censura. A Jest of God, de Mar- 
garet Laurence, enfoca a individualidade feminina e as restrições de gênero impostas pela sociedade, dentro do contexto ideológico de um regime político que projetou imagens de mulheres como anjos em casa ou prostitutas (Morcillo 2016, p.51). Dessa forma, as questões sexuais e de gênero em $A$ Jest of God transformaram o romance em um texto "com uma poderosa essência política" (Hughes, 1988, p. 125).

O artigo seguinte é de autoria de Lourdes Royano Gutiérrez e se intitula $A$ doença feminina na literatura: $O$ uso de venenos nos romances. Este artigo refere-se a dois casos relacionados a venenos na literatura: o romance Madame Bovary, de Gustave Flaubert (1857), e o conto The Thumb Mark de São Pedro de Agatha Christie (1932). No romance moderno, uma das perspectivas mais produtivas para analisar é a morte do protagonista. Como o autor descarta sua criação? um método muito comum é o veneno. O tema dos venenos na literatura não é novo, pois é uma área de estudo que tem capturado o interesse de muitos especialistas em literatura e leitores em geral (Gamoneda, 1995). Assim, o artigo traça um paralelo entre o uso de venenos e a associação com personagens femininas na literatura, investigando uma ideia presente em muitas obras literárias em que o veneno é uma arma feminina e que representa a natureza "fraca" e "traiçoeira" da mulher.

O artigo de Sergio Lobejón Santos tem como título: $O$ papel das mulheres na tradução de poesia de Língua Inglesa no pós-guerra espanhol. A Guerra civil espanhola (1936-1939) afetou profundamente a cultura do país; as dificuldades econômicas enfrentadas pela Espanha após o conflito transformaram os livros em itens de luxo, reduzindo drasticamente o potencial público de leitura. Este artigo examina o papel das mulheres neste clima editorial, focalizando obras de poesia traduzidas do inglês e explorando as contribuições feitas por mulheres como poetas e tradutoras. Valores conservadores impostos pela ditadura exigiam que as mulheres se encaixassem em dois papéis: as donas de casa obedientes e as mães 
auto-sacrificadas, cuja realização exigia proteção masculina (Escaja 2009, 359; Palacio Lis, 2003, p. 173-175).

No entanto, a tendência à independência feminina começou após os anos 1960, quando as mulheres progressivamente passaram a desempenhar um papel mais ativo fora do âmbito doméstico, com muitas começando suas carreiras profissionais e ajudando outras mulheres a fazer o mesmo, alcançando um grau mais significativo de emancipação (Mangini González, 1987, p. 135). A era pós-guerra civil foi particularmente difícil para as escritoras, elas tinham que se conformar não apenas à censura do regime de Franco, mas também ao ambiente sociocultural restritivo ao qual deviam aderir como mulheres.

Durante a última parte do século XIX, a poesia escrita por mulheres exceto alguns casos excepcionais, foram sumariamente considerada como um mero passatempo, e teve negado o acesso ao cânone literário (Acillona, 2003, p.86). As mulheres eram tradicionalmente consideradas ou o objeto passivo do desejo masculino na poesia lírica ou as autoras de poemas sentimentais. As poetas femininas começaram a ganhar sua própria voz, particularmente no início dos anos 1950 e começaram a rejeitar os elementos dessa dicotomia como suas únicas opções viáveis. Além disso, eles denunciaram distinções terminológicas destinadas a manter a poesia masculina e a feminina separadas. Isso foi encapsulado na palavra poetisa, tradicionalmente usada em espanhol para descrever uma poetisa como a contraparte feminina de poeta. A contribuição das mulheres escritoras foi crucial durante os anos que se seguiram à guerra civil, pois elas estavam entre os autores do processo coletivo de reconstrução lenta do mercado editorial e literário. Nos anos que se seguiram à morte de Franco, especialmente a partir dos anos 1980, houve um movimento para reavaliar o trabalho de muitas mulheres poetas e recuperar a obra de muitos exilados, como Concha Méndez e Ernestina de Champourcín. A poesia traduzida era um nicho no mercado literário espanhol; dos 169 tradutores 
do Catálogo, 42 (25\%) são mulheres. Este número é muito mais alto do que o percentual de escritoras femininas, que correspondia a cerca de $10 \%$ do total de autores traduzidos, cujas obras representavam menos de $4 \%$ de todos os títulos de poesia traduzidos do inglês. Dado o número de traduções produzidas por mulheres, fica claro que a tradução era uma atividade na qual as mulheres eram mais consistentemente engajadas. A contribuição dessas mulheres, em termos de obras traduzidas é de 119 edições, uma média de quase três para cada tradutor masculino (Gurruchaga, 2007, p.28). Por fim, as tiragens limitadas de livros de poesia fizeram com que esses títulos fossem autorizados sem nenhum obstáculo, pois eram considerados inofensivos pelo regime.

O primeiro artigo da terceira parte, de Eleonora Federici tem por título $O$ contexto é importante: a tradução feminista entre a ética e a política na Europa. A tradução sempre foi um instrumento para ampliar os cânones literários e transpor os conhecimentos de uma cultura para outra. As literaturas cruzaram as fronteiras nacionais através da tradução e foram influenciadas umas pelas outras.

Se olharmos para a presença de questões de gênero nos programas de estudos de tradução, não há cursos oficiais sobre o assunto, mas as teorias e práticas feministas podem ser incluídas em cursos mais gerais sobre tradução. O panorama europeu sobre mulheres tradutoras, através do tempo e do espaço, mostra seu papel como agentes culturais e intelectuais em diálogo com escritores, filósofos e homens do pensamento de seu tempo. A partir de meados dos anos 80, alguns livros sobre o papel das mulheres na tradução foram publicados. Esses trabalhos enfatizaram a importância das mulheres tradutoras em períodos históricos em que a noção de autoria feminina não era sequer levada em conta. Eles demonstraram que, como a tradução era considerada uma atividade secundária, as mulheres podiam entrar passo a passo e se tornar agentes culturais de seu tempo. 
O último artigo de autoria de Irene Arcos, tem por título: Tradução e Ideologia a construção da identidade nas revistas destinadas às mulheres. Neste artigo, a autora reflete sobre as mensagens atuais espalhadas por um gênero particular de publicação: revistas impressas voltadas para mulheres na Espanha. O estudo discute a relação existente entre a publicidade exposta nessas revistas e os mecanismos utilizados para impor certos discursos e modelos de identidade feminina que perpetuam o consumo de produtos de beleza e cosméticos. Como representações da mídia global, essas revistas precisam traduzir e adaptar seus conteúdos para estarem presentes em um nível local, isto é, em vários países diferentes em uma infinidade de idiomas. Assim, é uma discussão importante para a investigação de como a tradução contribui para a continuidade de valores e ideias.

Translation, Ideology and Gender discorre sobre temas importantes para o atual momento histórico rico em estudos sobre a representação da mulher e a questão de gênero. Destacando a parcialidade da tradução na dialética do poder, a questão de gênero nos estudos da tradução tem avançado nas últimas décadas, mostrando ser um campo de estudos promissor. Através da leitura do livro percebemos que a linguagem como uma ferramenta de poder e manipulação ideológica está longe de ser neutra e objetiva. A linguagem é uma ferramenta muito poderosa de comunicação e sua manipulação reside no seu uso, semântica, ideologia e conotações. Os tradutores se tornam agentes globalizantes quando disseminam ideologias em nível global e, em alguns casos, esses discursos promovem conflitos, em vez de aceitação e respeito por diferentes grupos oprimidos. 


\section{Referências}

CAMUS, Carmen; CASTRO Cristina; CAMUS Julia. Translation Ideology and Gender, Newcastle: Cambridge Scholars Publishing, 2017, 201 p.

Recebido em: 30/04/2018

Aceito em: 28/07/2018

Publicado em setembro de 2018

Alane Melo da Silva. E-mail: alanepoet@gmail.com

ORCID: https://orcid.org/0000-0002-9702-9816 